\title{
NHẬN XÉT CÁC BIỆN PHÁP ĐIỀU TRI NGộ ĐộC CẤP METHANOL TẠI TRUNG TÂM CHỐNG ĐộC BỆNH VIỆN BẠCH MAI
}

\section{TÓM TẮT.}

Việt Nam chưa có thuốc giải độc đặc hiệu fomepizol, điều trị ngộ độc methanol vào các biển pháp chính là hồi sức, lọc máu ngoài cơ thể, dùng bicarbonat tích cực và ethanol đường uống. Muc tiêu: Nhận xét tỷ lệ, đặc điểm và kết quả của các biên pháp điều trị áp dụng cho bệnh nhân ngộ độc cấp methanol tại Trung tâm chống độc (TTCĐ). Đốí tượng và phướng pháp: Nghiên cứu mô tả trên 107 bệnh nhân ngộ độc cấp methanol điều trị tại TTCĐ bềnh viên Bach Mai từ 01/2016 đến 07/2019. Kết quả: Các biện pháp điêu trị ở ngộ độc cấp methanol: Thở máy $78,5 \%$; dùng thuốc vân mach $43,9 \%$, tỉ lê bệnh nhân phải thở máy và dùng thuốc vận mạch nhóm tử vong cao hơn nhóm sống $(\mathrm{p}<0,0 \mathrm{i})$. Dưng bicarbonat điều trị toan máu ở 99,1\% số bệnh nhân, tỉ lệ bệnh nhân dùng bicarbonat $>500 \mathrm{mEq}$ và lượng bicarbonat phải dùng của nhóm tử vong cao hơn nhóm sống $(p<0,05)$; có $82,2 \%$ bệnh nhân được dùng ethanol $20 \%$ đường uống, lượng ethanol trung bình là 1093,8ml; 99,1\% bệnh nhân cần phải lọc máu, trong đó $90,7 \%$ là lọc máu ngắt quãng $H D$ và $8,4 \%$ loc máu liên tục CVVH. Thời gian lọc máu HD trung bình $7,6 \pm 3,34$ giờ. Tỉ lệ tử vong cao $(41,1 \%)$. Kết luận: Điều trị ngộ độc cấp methanol cần sự phối hợp của các biện pháp hồi sức tích cực, sử dụng thuốc kháng độc và lọc máu.

Tư khóa: ngộ độc cấp, methanol, điều trị.

\section{SUMMARY}

\section{TREATMENT MEASURES FOR METHANOL} POISONING AT POISON CONTROL CENTER OF BACH MAI HOSPITAL

Fomepizol is not available in Vietnam, therefore, the treatment of methanol poisoning focuses on the main measures: resuscitation, dialysis, aggressive use of bicarbonate and oral ethanol. Objective: to evaluate the rates, characteristics and outcomes of the treatment measures applied to patients with acute methanol poisoning at the Poison Control Center (PCC). Subjects and Methods: A observational study included 107 methanol poisoned patients treated at the PCC of Bach Mai Hospital from January 2016 to July 2019. Results: The applied treatment measures for acute methanol intoxication were mechanical ventilation (78.5\%); using vasopressors $(43.9 \%)$. The rate of patients required ventilation and

\footnotetext{
${ }^{1}$ Trung Tâm Chông Độc - Bệnh viện Bạch Mai, ²Bệnh viện Lão khoa Trung ương Chịu trách nhiệm chính: Đặng Thị Xuân Email: xuandangthi17@gmail.com Ngày nhận bài: 28.12.2020 Ngày phản biện khoa học: 22.2.2021 Ngày duyệt bài: 1.3.2021
}

\section{Đặng Thị Xuân ${ }^{1}$, Nguyễn Trung Anh²}

using vasopressors were higher in the fatal group than that in the survival group $(p<0.01)$. Bicarbonate was used to rapidly correct acidosis in $99.1 \%$ of the patients. The percentage of using bicarbonate more than $500 \mathrm{mEq}$ and the amount of bicarbonate to be used in the fatal group was higher than the survival group ( $p<0.05$ ); $82.2 \%$ of patients received $20 \%$ orally ethanol, the average amount of ethanol was $1093.8 \mathrm{ml} ; 99.1 \%$ of patients need dialysis, of which $90.7 \%$ were intermittent hemodialysis and $8.4 \%$ were $\mathrm{CVVH}$. Average duration of hemodialysis was $7.6 \pm$ 3.34 hours. The mortality rate of methanol poisoning was high (41.1\%). Conclusion: acute methanol poisoning was life-threatening and the treatment required a combination of aggressive resuscitation measures, use of antidotes and dialysis.

Keywords: acute poisoning, methanol, treatment.

\section{I. ĐẶT VẤN ĐỀ}

Methanol là cồn công nghiệp, được sử dụng rộng rãi để làm dung môi, làm chất chống đóng băng nhiên liệu động cơ đốt trong..., trên toàn cầu có hàng trăm triệu triệu lít methanol sử dụng mỗi ngày. Methanol có độc tính cao, không được sử dụng làm rượu thực phẩm. Methanol được hấp thu nhanh chóng và hoàn toàn qua đường tiêu hóa, nồng độ đỉnh đạt được sau 30 90 phút, tuy nhiên các triệu chứng ngộ độc thường xuất hiện chậm sau khoảng 18 - 24 giờ.

Ngộ độc methanol thường do uống nhầm cồn sát trùng, uống rượu ethanol bị pha lẫn methanol. Trên thế giới, có nhiều vụ ngộ độc với số lượng bệnh nhân lớn như ở Campuchia, Cộng hòa Séc, Iran, Ấn Độ,... với tỷ lệ tử vong cao. Ớ Việt Nam, theo Bộ Y tế hàng năm có khoảng trển 1000 ca ngộ độc methanol. Tại Trung tâm chống độc Bệnh viện Bạch Mai, theo nghiên cứu của Phạm Như Quỳnh từ 2016 đến 2017 có 37 BN ngộ độc methanol, tỉ lệ tử vong lên đến $35,2 \%$ và di chứng là $37,8 \%$ [1].

Điều trị ngô đốc methanol tâp chung vào 4 biên pháp chính là hồi sức, lọc máu ngoài cơ thể, ức chế enzym $A D H$ và dùng bicarbonat tích cực. Methanol có thể tích phân bố thấp, từ 0,6 $0,7 \mathrm{~L} / \mathrm{kg}$, không gắn với protein huyết tương nên lọc máu rất hiệu quả để đào thải methanol, ngoài ra lọc máu còn có thể hỗ trợ thận và các cơ quan khác trong cơ thể. Enzym chuyển hóa chung của methanol và ethanol là $A D H$ có ái lực với ethanol gấp 7-10 lần nên ethanol được dùng như một thuốc kháng độc đặc hiệu trong điều trị cấp cứu ngộ độc methanol. Việc đánh giá hiệu 
quả các biện pháp điều trị giúp các bác sĩ lâm sàng áp dụng phù hợp các biện pháp trong cấp cứu bệnh nhân. Trên thế giới có một số nghiên cứu về các biện pháp điều trị ngộ độc methanol. Trong điều kiện ở Việt Nam, còn thiếu thuốc kháng độc đặc hiệu như fomepizol, ethanol đường tĩnh mạch, còn ít nghiên cứu tống thể về điều trị ngộ độc cấp methanol, do vậy chúng tôi tiến hành nghiên cứu nhằm mục tiểu nhận xét các biện pháp điều trị bệnh nhân ngộ độc cấp methanol ở bệnh nhân ngộ độc cấp methanol tại Trung tâm chống độc bệnh viện Bạch Mai.

\section{II. ĐỐI TƯợNG VÀ PHƯƠNG PHÁP NGHIÊN CỨU}

2.1. Đối tượng nghiên cứu: Bệnh nhân ngộ độc cấp methanol điều trị tại Trung tâm Chống độc bệnh viện Bạch Mai từ tháng 1/2016 đến $7 / 2019$.

\section{Tiêu chuẩn chọn bệnh nhân}

- Bệnh sử có uổng rượu hoặc hóa chất nghi ngờ có methanol.

- Định lượng có methanol trong máu.

Tiêu chuẩn loại trừ

- Ngộ độc phổi hợp với chất khác (ngoài ethanol): thuốc ngủ, hóa chất bảo vệ thực vật...

- Tiền sử bệnh có di chứng thần kinh trung ương và di chứng thần kinh thị giác từ trước

\subsection{Phương pháp nghiên cứu}

Thiết kế nghiên cứu: Nghiên cứu mô tả

Phương pháp chọn mẫu: chọn mẫu toàn bộ

Nội dung và tiến hành nghiên cứu: bệnh nhân đủ tiêu chuẩn lựa chọn được tiến hành thu thập số liệu theo mẫu bệnh án thống nhất:

- Các thông tin hành chính: Họ tên, tuổi, giới, địa chỉ, nghề nghiệp

- Tiền sử bệnh, nguyên nhân ngộ độc, loại đồ uống gây ngộ độc, thời gian từ khi ngộ độc đến khi vào viện, chẩn đoán và xử trí trước khi vào viện.

- Triệu chứng lâm sàng: Thần kinh, thị giác, hô hấp, tuần hoàn, tiêu hóa, thận, tiêu cơ vân

- Cận lâm sàng: Công thức máu, đông máu cơ bản, sinh hóa (ure, creatinin, glucose, CK, AST, ALT, bilirubin, điện giải đồ, lactat máu), khí máu động mạch, áp lực thẩm thấu (ALTT) máu, khoảng trống (KT) ALTT, khoảng trông anion, khám mắt, chụp $\mathrm{CT} / \mathrm{MRI}$ sọ và các thăm dò biến chứng, đánh giá hiệu quả điều trị.

Định lượng methanol và ethanol máu bằng sắc kí khí tại viện Giám định Pháp Y.

- Điều trị:

+ Hồi sức chung: thở oxy, thở máy, truyền dịch, thuốc vận mạch, truyền bicarb ...
+ Điều trị giải độc đặc hiệu (ethanol 20\% đường uống), acid folinic

+ Lọc máu: ngắt quãng, loc máu liên tuc

- Kết quả điều trị: khỏi, di chứng, tử vong, di chứng.

Phương tiện nghiên cứu: Các xét nghiệm được làm tại khoa Huyết học, Hóa sinh, Xquang, thăm dò chức năng của bênh viên Bach Mai.

2.3. Xử lí số liệu. Số liệu được xử lý theo phương pháp thống kê y học, sử dụng phần mềm SPSS 20.0. So sánh giá trị 2 trung bình bằng Student test (Mann-Witney $U$ test nếu phân bố không chuẩn), so sánh tỉ lệ \% bằng test X2 hoặc Fisher Exact test, mức ý nghĩa thống kê 95\%.

\section{KẾT QUẢ NGHIÊN CứU}

Trong thời gian từ 01/2016-07/2019, có 107 bệnh nhân đủ tiêu chuẩn chọn vào nghiên cứu. Một số kết quả thu được như sau:

3.1. Đặc điểm chung của bệnh nhân nghiên cứu

Phân bố theo giới: Bênh nhân nam là chủ yếu 104/107 BN (97,2\%); Nữ 3/107 BN (2,8\%). Tỉ lệ giới Nam/nữ là 34,7:1

- Phân bố theo tuổi: Tuổi trung bình của bênh nhân nghiên cứu là $47,6 \pm 12,6$ tuổi (1672). Bệnh nhân chủ yếu ở nhóm tuổi trung niên 40-59 tuổi $(65,4 \%)$.

- Kết quả điêuu trị:

Tử vong $44 \mathrm{BN}(41,1 \%)$; sống $63 \mathrm{BN}$ (58,9\%). Trong 63 BN sống, có 22 BN sống không di chứng $(20,6 \%)$ còn $41 \mathrm{BN}$ có di chứng $(38,3 \%)$.

3.2. Một số biện pháp điêu trị bệnh nhân ngộ độc methanol

Bảng 3.1. Các biện pháp điều trị bệnh nhân ngộ độc methanol

\begin{tabular}{|c|c|c|}
\hline $\begin{array}{c}\text { Các biện pháp điều } \\
\text { trị }\end{array}$ & $\begin{array}{c}\text { Số bệnh nhân } \\
\text { (n=107) }\end{array}$ & $\begin{array}{c}\text { Tỉ lệ } \\
\text { \% }\end{array}$ \\
\hline Truyền bicarbonat TM & 106 & 99,1 \\
\hline Lọc máu & 106 & 99,1 \\
\hline $\begin{array}{c}\text { Dùng ethanol đường } \\
\text { uống }\end{array}$ & 88 & 82,2 \\
\hline Thớ máy & 84 & 78,5 \\
\hline Dùng thuốc vận mạch & 47 & 43,9 \\
\hline Truyền acid folinic TM & 38 & 35,5 \\
\hline
\end{tabular}

Nhân xét: Các bệnh nhân được điều trị theo phác đồ của Trung tâm Chống độc: Hồi sức, truyền bicarbonat, dùng thuốc kháng độc và lọc máu. Tất cả các $B N$ đều được truyền bicarbonat $(100 \%)$, lọc máu $99,1 \%$, ethanol đường uống $82,2 \%$, thở máy $78,5 \%$, và $43,9 \%$ phải dùng thuốc vận mạch. 
Bảng 3.2. Các biên pháp hồi sức và điều trị hỗ trơ ở nhóm bênh nhân sống và tử vong

\begin{tabular}{|c|c|c|c|c|}
\hline Nhỉ số & $\begin{array}{c}\text { Tống cộng } \\
\text { (n=107) }\end{array}$ & $\begin{array}{c}\text { Sống } \\
(\mathbf{n = 6 3 )}\end{array}$ & $\begin{array}{c}\text { Tứ vong } \\
(\mathbf{n = 4 4 )} \text { (2) }\end{array}$ & $\begin{array}{c}\text { p (1) và } \\
\text { (2) }\end{array}$ \\
\hline Dùng thuốc vận mạch & $47(43,9 \%)$ & $7(11,1 \%)$ & $40(90,9 \%)$ & $<\mathbf{0 , 0 0 1}$ \\
\hline Thở máy & $84(78,5 \%)$ & $40(63,5 \%)$ & $44(100 \%)$ & $<\mathbf{0 , 0 1}$ \\
\hline Dùng bicarbonat truyền TM & $106(99,1 \%)$ & $62(98,4 \%)$ & $44(100 \%)$ & $>0,05$ \\
\hline Lượng bicarbonat cần dùng $>500 \mathrm{mEq}$ & $44(41,1 \%)$ & $17(27,0 \%)$ & $27(61,4 \%)$ & $<\mathbf{0 , 0 5}$ \\
\hline Lượng bicacbonat truyền (mEq) & 642,5 & 525,3 & 810,2 & $<\mathbf{0 , 0 5 *}$ \\
\hline
\end{tabular}

(*Mann-Witney U test)

Nhận xét: -Tỉ lệ $B N$ phải dùng thuốc vận mạch và thở máy của nhóm tử vong cao hơn nhóm sống nhiều $(90,9 \%$ so với $11,1 \%, p<0,001)$ và $(100 \%$ so với $63,5 \% ; p<0,01)$.

- Tỉ lệ BN dùng bicarbonat không khác nhau tuy nhiên tỉ lệ dùng bicarbonat $>500 \mathrm{mEq}$ và lượng bicarbonat phải dùng của nhóm tử vong cao hơn nhóm sống $(61,4 \%$ so với $27,0 \% ; p<0,05)$ và $(810,2 \mathrm{mEq}$ so với $525,3 \mathrm{mEq} ; \mathrm{p}<0,05)$.

Bảng 3.2. Sử dụng thuốc giải dộc

\begin{tabular}{|c|c|c|c|c|}
\hline \multicolumn{1}{|c|}{ Nhóm } & $\begin{array}{c}\text { Tống cônng } \\
\text { (n=107) }\end{array}$ & $\begin{array}{c}\text { Sống } \\
\text { (n=63) (1) }\end{array}$ & $\begin{array}{c}\text { Tứ vong } \\
(\mathbf{n = 4 4 )} \text { (2) }\end{array}$ & p (1) và (2) \\
\hline $\begin{array}{c}\text { Dùng ethanol 20\% đường uống } \\
\text { (qua sonde dạ dày) }\end{array}$ & $88(82,2 \%)$ & $50(79,4 \%)$ & $38(86,4 \%)$ & $>0,05$ \\
\hline Lượng ethanol 20\%(ml) & 1093,8 & 1044,1 & 1165,0 & $>0,05^{*}$ \\
\hline Dùng acid folinic & $38(35,5 \%)$ & $14(22,2 \%)$ & $24(54,5 \%)$ & $>0,05$ \\
\hline
\end{tabular}

(*Mann-Witney U test)

Nhận xét: Chúng tôi sử dụng ethanol $20 \%$ qua sonde dạ dày cho 88/107 BN $(82,2 \%)$, một số bệnh nhân không dùng được vì xuất huyết tiêu hóa, viêm tụy cấp.

- Lượng ethanol trung bình cho 1 bệnh nhân là 1093,8 ml; lượng ethanol của nhóm BN tử vong và nhóm sống không khác nhau, $\mathrm{p}>0,01$.

- Có 38 BN $(35,5 \%)$ được sử dụng acid folinic điều trị cho các BN

Bảng 3.4. Các biệ̂n pháp lọc máu ở bệnh nhân ngộ độc methanol

\begin{tabular}{|c|c|c|c|c|}
\hline $\begin{array}{c}\text { Nhóm } \\
\text { Chỉ số }\end{array}$ & $\begin{array}{c}\text { Tống cộng } \\
\text { (n=107) }\end{array}$ & $\begin{array}{c}\text { Sống } \\
(\mathbf{n = 6 3 )}(1)\end{array}$ & $\begin{array}{c}\text { Tử vong } \\
\left(\mathbf{n = 4 4 )} \mathbf{~ ( 2 ) ~}^{(2)}\right.\end{array}$ & $\mathbf{p}^{(1) \text { và (2) }}$ \\
\hline Lọc máu & $106(99,1 \%)$ & $62(98,4 \%)$ & $44(100 \%)$ & $>0,05$ \\
\hline Lọc máu liên tục CVVH & $9(8,4 \%)$ & $2(3,2 \%)$ & $7(15,9 \%)$ & $>0,05$ \\
\hline Lọc máu ngắt quãng HD & $97(90,7 \%)$ & $60(95,2 \%)$ & $37(84,1 \%)$ & $>0,05$ \\
\hline Thời gian lọc máu ngắt quãng HD (giờ) & $7,6 \pm 3,34$ & $7,97 \pm 3,22$ & $7,14 \pm 3,51$ & $>0,05$ \\
\hline
\end{tabular}

Nhân xét: Có $99,1 \%$ cần phải loc máu, trong đó chủ yếu $(90,7 \%)$ là lọc máu ngắt quãng $H D$, chỉ có $8,4 \%$ lọc máu liên tục $C V V H$. Thời gian lọc máu $H D$ trung bình là 7,6 giờ. Tỉ lệ lọc máu và thời gian lọc máu nhóm sống và tử vong không khác nhau.

\section{BÀN LUẬN \\ 4.1 Đặc điểm chung của bệnh nhân nghiên cứu}

- Phân bố về giới tính: Bệnh nhân nam chiếm chủ yếu trong nghiên cứu của chúng tôi 104BN $(97,2 \%)$ và chỉ có $3 B N$ nữ $(2,8 \%)$. Ớ Việt Nam, nam uống rượu nhiều hơn nữ, ngộ độc methanol hay rượu nói chung chủ yễu ở nam giới. Tác giả Phạm Như Quỳnh nam giới là 96,67\% [1], của Lee C.Y. nam giới 87,5\% [5] tương tự kết quả của chúng tôi.

Phân bố về tuổi: tuổi trung bình của các bênh nhân là 47,6 \pm 12,6 tuổi, nhóm tuổi trung niên 40-59 tuổi gặp nhiều nhất $(65,4 \%)$, tương

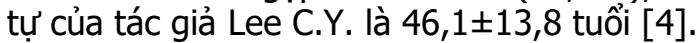

- Kết quả điều trị: Tỉ lệ tử vong trong nghiên cứu của chúng tôi là 44/107BN $(41,1 \%)$. Kết quả của chúng tôi cao hơn của Phạm Như Quỳnh (2017), tứ vong 35,2\% [1]; cao hơn nhiều với kết quả nghiên cứu của Zakharov tử vong $14,3 \%$, di chứng 33,3\% [8], chúng tôi nghĩ do thói quen nhiều người uống rượu trôi nổi, đến viện muộn, thiếu xét nghiệm và thuốc giải độc đặc hiệu đường tĩnh mạch như ethanol truyền tĩnh mạch, fomepizole.

4.2. Các biện pháp điều trị bệnh nhân ngộ độc methanol. Các bệnh nhân của chúng tôi được điều trị theo phác đồ của Trung tâm Chống độc: hồi sức, điều trị biến chứng và toan máu, dùng thuốc kháng độc, lọc máu. Vì ngộ độc methanol thường nặng, nhiều biến chứng nển tî̉ lệ $\mathrm{BN}$ phải dùng thuốc vận mạch cao 
$(43,9 \%)$ và thở máy $78,5 \%$; của nhóm tử vong cao hơn nhóm sống nhiều (90,9\% so với $11,1 \%$, $p<0,001)$ và $(100 \%$ so với $63,5 \% ; p<0,01)$.

Biện pháp tăng đào thải chất độc mà chúng tôi áp dụng cho hâuu hết các loại ngộ độc là rửa dạ dày và uống than hoạt khi bệnh nhân ngộ độc qua đường uống thì không áp dụng được với ngộ độc methanol vì methanol hấp thu rất nhanh và than hoạt không hấp phụ được methanol.

Các $B N$ của chúng tôi được truyền $T M$ bicarbonat điều trị tình trạng toan máu ngay từ lúc vào, trong lúc đợi thiết lập lọc máu. Tỉ lệ bệnh nhân dùng bicarbonat $>500 \mathrm{mEq}$ và lượng bicarbonat phải dùng của nhóm tử vong cao hơn nhóm sống $(61,4 \%$ so với $27,0 \% ; p<0,05)$ và $(810,2 \mathrm{mEq}$ so với 525,3 mEq; $\mathrm{p}<0,05)$. Nhóm $\mathrm{BN}$ tử vong có $92,2 \%$ vào viện muộn sau uống $>24$ giờ, ở nhóm sống là 65,1\%. Tình trạng lâm sàng các $B N$ tử vong cũng nặng hơn, phải dùng thuốc vận mạch và thở máy nhiều hơn, chính vì vậy các biện pháp can thiệp và lượng bicarbonat phải dùng cũng nhiều hơn, đặc biệt là trong 4 giờ đâu. Methanol khi vào cơ thể sẽ chuyển hóa thành acid formic rất độc, máu càng toan thì acid formic càng dễ qua màng tế bào. Dùng bicarbonat làm giảm tình trạng toan máu, hạn chế xâm nhập của acid formic vào tế bào, đặc biệt là ở vùng nhân xám trung ương và thần kinh thị giác [2], [6].

Chúng tôi sứ dụng thuốc giải độc ethanol $20 \%$ đường uống (qua sonde dạ dày) cho $88 \mathrm{BN}$ $(82,2 \%)$, điều chỉnh liều theo lọc máu và cân nặng bệnh nhân nên liều và tỉ lệ không khác nhau. Lượng ethanol trung bình là 1093,8 \pm $631,4 \mathrm{ml}$. N $g$ hiên cứu của Lee Chen-Yen có $59,4 \%$ BN được dùng ethanol, thấp hơn của chúng tôi, có thể tác giả nghiên cứu từ những năm trước [5]. Tác giả Zakharov nhận thấy nồng độ ethanol dương tính khi nhập viện là yếu tố dự báo khả năng sống, hạn chế di chứng thần kinh, thị giác khi điều chỉnh được pH máu động mạch [8].

Trong nghiên cứu của chúng tôi đã có $38 \mathrm{BN}$ $(35,5 \%)$ được dùng acid folinic. Acid folic giúp đẩy nhanh quá trình chuyển hóa của acid formic thành $\mathrm{CO} 2$ và nước. Acid folinic là dang hoat động của acid folic có tác dung thúc đẩy chuyển hóa acid formic mà không cần trải qua phản ứng giáng hóa nhờ men dihydrofolate reductase như acid folic do đó có thể dùng ngay khi bệnh nhân vào viện, tuy nhiên thuốc chưa được sử dụng thường quy.

Tuy nhiên, sử dụng ethanol của chúng tôi còn một số hạn chế do chỉ có ethanol đường uống, chưa có loại truyền tĩnh mạch, nên khó đạt liêu điều trị $100-150 \mathrm{mg} / \mathrm{dL}$. Ngoài ra, một số BN xuất huyết tiêu hóa, rối loạn tiêu hóa nặng nên không thể dùng được. Khi dùng ethanol đường uống cũng cần phải theo dõi rất sát bệnh nhân để tránh các biến chứng như: hạ đường huyết, viêm tụy cấp, rối loạn tiêu hóa, tằng men gan...[7]

Chúng tôi có $106 / 107$ BN $(99,1 \%)$ phải lọc máu, trong đó $97 \mathrm{BN}(90,7 \%)$ lọc máu ngắt quãng $\mathrm{HD}$ và $9 \mathrm{BN}(8,4 \%)$ lọc máu liên tục CVVH. Thời gian loc máu ngắt quảng $\mathrm{HD}$ dài trung bình 7,6 $\pm 3,34$ giờ. Lọc máu HD đào thải methanol rất tốt, giảm thời gian bán thải của methanol từ 28,5 giờ xuống chỉ còn 2,8 giờ, trong khi lọc máu liên tục là 13,5 giờ [3], [6], chính vậy chúng tôi thường cố gắng nâng huyết áp lên (kể cả phải tăng thuốc vận mạch) để có thể loc máu HD cho bênh nhân và kéo dài thời gian lọc HD 6-8 giờ để tăng đào thải methanol. Chúng tôi chỉ lọc CVVH cho các BN huyết áp quá thấp, suy tim, tình trạng quá nặng.

\section{KẾT LUÂN}

84BN (78,5\%) phải thở máy, 47BN (43,9\%) phải dùng thuốc vận mạch. Tỉ lệ bệnh nhân phải thở máy và dùng thuốc vận mạch nhóm tử vong cao hơn nhóm sống $p<0,01$.

99,1\% số bệnh nhân dùng bicarbonat điều trị toan máu, tỉ lệ bệnh nhân dùng bicarbonat $>500 \mathrm{mEq}$ và lượng bicarbonat phải dùng của nhóm tử vong cao hơn nhóm sống $(p<0,05)$.

88BN (82,2\%) được dùng ethanol $20 \%$ đường uống, lượng ethanol trung bình là 1093,8ml

- 99,1\% bệnh nhân cần phải lọc máu, trong đó $90,7 \%$ là lọc máu ngắt quãng $H D$ và $8,4 \%$ loc máu liên tục $\mathrm{CVVH}$. Thời gian lọc máu $\mathrm{HD}$ trung bình 7,6 $\pm 3,34$ giờ

\section{TÀI LIỆ THAM KHẢO}

1. Phạm Như Quỳnh, Lê Đình Tùng, Hà Trân Hưng (2017). Hiêu quả của thẩm tách máu kéo dài trong điều trị bệnh nhân ngộ độc cấp methanol. Tạp chí Sinh lý học Việt Nam, 21(3), 13-20.

2. Barceloux D.G, et al. (2002). American Academy of Clinical Toxicology practice guidelines on the treatment of methanol poisoning. J Toxicol Clin Toxicol, 40(4), 415-46.

3. Goodman J.W., Goldfarb D.S. (2006). The role of continuous renal replacement therapy in the treatment of poisoning. Semin Dial. 19(5), 402-7.

4. Kute V. B., et al (2012). Hemodialysis for methyl alcohol poisoning: a single-center experience. Saudi $]$ Kidney Dis Transpl. 23(1), 37-43

5. Lee C.Y., Chang E.K., Lin J.L., et al (2014). Risk factors for mortality in Asian Taiwanese patients with methanol poisoning. Ther Clin Risk Manag, 10, 61-7. 
6. McMartin K., Jacobsen D, Hovda K.E, et al (2016). Antidotes for poisoning by alcohols that form toxic metabolites. $\mathrm{Br} \mathrm{J}$ Clin Pharmacol; 81(3):505-15.

7. Wedge M.K., Natarajan S., Johanson $C_{\text {., }}$ et al (2012). The safety of ethanol infusions for the treatment of methanol or ethylene glycol intoxication: an observational study. CJEM; 14(5):283-9

8. Zakharov S., Nurieva O., Kotikova K., et al (2017). Positive serum ethanol concentration on admission to hospital as the factor predictive of treatment outcome in acute methanol poisoning. Monatsh Chem, 148(3):409-419.

\section{ĐIỀU TRI BÓC TÁCH ĐộNG MẠCH CHỦ CẤP TÍNH BẰNG PHẪU THUÂTT MỞ KẾT HỢP ỐNG GHÉP LAI}

\section{TÓM TẮT.}

Đăt vấn đề: Bóc tách động mạch chủ ngực cấp tính là một cấp cứu tim mạch nguy cơ cao, đặc biệt là thể lâm sàng Stanford A- De Bakey I. Bên cạnh phẫu thuật mổ mở kinh điển, phẫu thuật hybrid (mổ mở kết hợp đặt ống ghép lai) là phương pháp giải quyết thêm thương tổn ở động mạch chủ xuống. Tuy nhiên, cần có nghiên cứu hiệu quả của phương pháp này. Phương pháp nghiên cứu: Hồi cứu các trường hợp phẫu thuật mổ mở kết hợp đặt ống ghép lai nội mạch đông mach chủ từ tháng $5 / 2020$ đến tháng 9/2020 tai khoa Hổi sức- Phẫu thuật Tim BVCR với chẩn đoán trước mổ là phình lóc đô̂ng mach chủ ngực cấp tính loại Stanford A - De Bakey I. Kết quả: Có 17 bệnh nhân trong nghiên cứu, nam/nữ $=13 / 4$. Tuổi trung bình $56,5 \pm 12,7$. Phân suất tống máu thất trái trước mổ $E F=63 \pm 3,9 \%$. Đường kính động mach chủ lên trung bình: 43,2 $\pm 1,8 \mathrm{~mm}$, tỷ lệ đường kính động mạch chủ ngức lên/diên tích da cơ thể là $24,14 \mathrm{~mm} / \mathrm{m}^{2}$ da. Thời gian kẹp động mạch chủ $118 \pm 39$ phút và thời gian chay máy là $220 \pm 30$ phút. Số lượng ống ghép đặt cho một bệnh nhân là 1 , chiều dài ống ghép: $175,7 \pm 16 \mathrm{~mm}$. Tỷ lệ tử vong là $2 / 17(11,7 \%)$. Kết luận: Phẫu thuật mổ mở kết hợp đặt ống ghép lai sản xuất tại chỗ là hiệu quả, điều trị tốt các trường hợp bệnh động mạch chủ bóc tách cấp tính Stanford ADeBakey I. Phương pháp này có thể nhân rộng cho các trung tâm tim mạch khác.

Tư khoá: bóc tách động mạch chủ, ông ghép lai, stentgraft

\section{SUMMARY}

\section{ROLE Of HYBRID PROTHESIS IN TREATMENT OF ACUTE STANFORD A-DE BAKEY I AORTIC DISSECTION}

Objectives: Acute aortic dissection is one of the most serious cardiovascular emergencies, especially the Stanford A - De Bakey I one. Beside the conventional approach, hybrid surgery (modified

*Trung tâm Tim mạch, Bệnh viện Chợ Rẫy Chịu trách nhiệm chính: Nguyễn Thái An Email: nthaian@yahoo.com Ngày nhận bài: 4.01.2021 Ngày phản biên khoa học: 26.2.2021 Ngày duyệt bài: 9.3.2021

\section{Nguyễn Thái An*, Trần Quyết Tiến*}

frozen elephant trunk technique) is considered to be an efficient solution for damages in descending aorta. However, it is necessary to conduct a research about the efficacy of this kind of surgery. Subject and method: We have reviewed retrospectively all the cases that had pre-operative diagnosis as Stanford De Bakey I aortic dissection and were treated by using hybrid surgery from 5/2020 to 9/2020 at Cardiac CareSurgery department of Cho Ray Hospital. Results: There are 17 patients in the study, 13 males and 4 females, whose average are is $56,5 \pm 12,7$. The preoperative left ventricular ejection fraction (EF) is $63 \pm 3,9 \%$. The average diameter of ascending aorta is $43,2 \pm 1,8 \mathrm{~mm}$ and the rate ascending aortic diameter/body surface is $24,14 \mathrm{~mm} / \mathrm{m}^{2}$. The clamping time is $118 \pm 39$ minutes and the time of extracoporeal circulation is $220 \pm 30 \mathrm{~min}$. The number of grafts for one patient is one, and the length is $175,7 \pm 16 \mathrm{~mm}$. The mortality is $2 / 17(11,7 \%)$. Conclusion: The hybrid surgery (modified frozen elephant trunk technique) is an effective solution and stronglyrecommeneded for the cases of Acute Stanford ADeBakey I aortic dissection. This approach can be transferred to other cardiac centers in Vietnam.

Keyword: Aortic dissection, hybrid prothesis, stentgraft.

\section{I. ĐẶT VẤN ĐỀ}

Bóc tách động mach chủ cấp tính kiểu $A$ theo phân loại Stanford (gọi tắt là Stanford $\mathrm{A}$ ) là một bệnh lý nặng nề với tỳ lệ tử vong cao, 12-19,8\% [1], [2]. Trong các trường hợp bóc tách Stanford A kéo dài đến động mạch chủ bunng, tức là kiểu I theo phân loại De Bakey (gọi tắt là De Bakey I), phẫu thuật càng phức tạp vì vừa phải giải quyết bệnh lý của động mạch chủ đoạn lên và quai đồng thời phải làm tăng lượng máu tưới các tạng trong ổ bụng. Để giải quyết vấn đề tưới máu tạng trong ố bụng, hiện nay, có nhiều phương pháp như: kỹ thuật vòi voi kinh điển, kỹ thuật vòi voi kèm stentgraft (frozen elephant trunkFET), kỹ thuật mổ mở kết hợp đặt giá đõ Ascyrus [3]. Tuy nhiên, chúng tôi sử dụng kỹ thuật mố mở với ống ghép lai để giải quyết vấn đề của động mạch chủ ngực xuống. Nghiên cứu 